\title{
Reflexões sobre capital social e turismo comunitário no Rio Grande do Norte, Nordeste do Brasil
}

\section{Reflections on social capital and community tourism in Rio Grande do Norte, Northeast of Brazil}

\author{
Clébia Bezerra da Silva (SILVA, C. B. da) ${ }^{*}$; \\ Moema Hofstaetter (HOFSTAETTER, M.) ${ }^{* *}$; \\ Orlando Alcobia (ALCOBIA, O.) ${ }^{* * *}$
}

\begin{abstract}
RESUMO - Compreender a influência do capital social no desenvolvimento do turismo comunitário, a partir da experiência ocorrida no município de Maxaranguape, no Estado do Rio Grande do Norte (Brasil), foi objetivo do presente artigo. A metodologia utilizada apresentou uma abordagem qualitativa preconizada por Bauer (2002), tendo utilizado, como instrumento de coleta de dados, entrevistas semiestruturadas e não diretivas junto aos atores envolvidos na ação. Para a leitura dos dados, foi utilizada a análise de conteúdo conforme proposto por Bardin (2009). Os resultados mostraram que as ações não tiveram continuidade para o desenvolvimento do turismo comunitário bem como foi constatada a falta de engajamento, tanto das pessoas quanto de organizações, suficiente para alavancar a implementação do turismo comunitário. Como conclusão teve-se que, no Assentamento Novo Horizonte II, o capital social foi baixo, o que contribuiu definitivamente para a não continuidade das ações de turismo comunitário.
\end{abstract}

Palavras-chave: Turismo; Turismo Comunitário; Capital Social; Maxaranguape.

ABSTRACT - The aim of this article is to understand the social capital's influence on the community tourism development, based on the municipality of Maxaranguape's experience, in the state of Rio Grande do Norte. The methodology used in this article is

\footnotetext{
Formação acadêmica: Bacharelado em Turismo, Especialização em Educação e Sustentabilidade Ambiental, Mestrado em Desenvolvimento e Meio Ambiente, todos pela Universidade Federal do Rio Grande do Norte (UFRN). Doutoranda em Turismo - PPGTUR-UFRN. Atividade profissional: Professora da Universidade Federal do Rio Grande do Norte, Membro do Laboratório de Pesquisas e Estudos Turísticos e Grupo de Pesquisa Turismo, Sociedade \& Território. Endereço físico para correspondência: UFRN - Centro de Ensino Superior do Seridó. Rua Manoel Lopes Filho, 138 (Valfredo Galvão). CEP: 59380-000 - Natal - Rio Grande do Norte - Brasil. Endereço eletrônico: clebia@ufrnet.br

** Formação acadêmica: Graduação em Filosofia pela Universidade Federal do Paraná (UFPR), Mestrado em Estudos Urbanos e Regionais pelo Departamento de Políticas Públicas da Universidade Federal do Rio Grande do Norte (UFRN) e doutoranda pelo Departamento de Turismo da Universidade Federal do Rio Grande do Norte (UFRN). Bolsista da Coordenação de Aperfeiçoamento de Pessoal de Nível Superior - CAPES. Endereço físico para correspondência: Rua Cabo do Bacopari, 2090 (Ponta Negra). CEP: 59094-070 - Natal - Rio Grande do Norte - Brasil. Endereço eletrônico: moema.natal@hotmail.com.

*** Formação acadêmica: Graduação em Gestão Hoteleira pela Universidade do Algarve (Portugal), Mestrado em Gestão Estratégica de Destinos Turísticos pela Escola Superior de Hotelaria e Turismo do Estoril (Portugal) e doutorando em Turismo pela Universidade Federal do Rio Grande do Norte. Atividade profissional: professor universitário na Escola Superior de Hotelaria e Turismo de Inhambane pertencente à Universidade Eduardo Mondlane (Moçambique). Endereço físico para correspondência: Rua do Sal, 160, Potilândia. CEP: 59076-540 - Natal - Rio Grande do Norte - Brasil. Endereço eletrônico: orlandoalcobia@ufrn.edu.br
} 
focused in a qualitative approach, profess by Bauer (2002), using semi-structured and non-directive interviews to collect data from the actors involved in the action. To analyze the collected data, we used the content analysis, as proposed by Bardin (2009). The results (i) show the actions didn't have continuity for the community tourism development, (ii) as well as the lack of engagement of both individuals and organizations sufficient to leverage the implementation of community tourism. As a conclusion, the Novo Horizonte settlement has a low social capital structure, which definitely contributed to the non-continuity of community tourism actions.

Key words: Tourism; Community Tourism; Social Capital; Maxaranguape. 


\section{INTRODUÇÃO}

O turismo foi um elemento que ganhou notoriedade e relevância no desenvolvimento de localidades que buscaram desenvolver-se social e economicamente.

As comunidades receptoras foram o âmago do fenômeno turístico encerrando, em si, uma dicotomia, pois, ao mesmo tempo em que o seu desenvolvimento foi a razão da aposta na exploração do setor turístico numa dada região, elas próprias configuraram-se como um importantíssimo atrativo turístico seguindo as tendências do turismo internacional. Desta forma, pode-se considerar que as comunidades locais foram atores ativos e deveriam ser os beneficiários principais no palco da atividade turística no mundo contemporâneo (POON, 1994; MUHANNA, 2007).

É, sob este prisma, que surgiu o modelo do turismo comunitário que visou concentrar, em si, ideais defendidos e relacionados com o desenvolvimento sustentável, a economia ecológica ou o desenvolvimento endógeno. Nele, esteve implícita uma forma de mobilização das comunidades para o enfrentamento das várias facetas do turismo, como especulação imobiliária, subemprego, desmatamento, dentre outros.

Para Maldonado (2009, p. 31), o turismo comunitário encerrou:

[...] toda forma de organização empresarial sustentada na propriedade e na autogestão sustentável dos recursos patrimoniais comunitários, de acordo com as práticas de cooperação e equidade no trabalho e na distribuição dos benefícios gerados pela prestação dos serviços turísticos.

Contudo, nem sempre foi fácil conseguir a necessária mobilização e a organização estrutural das comunidades receptoras, na idealização, no planejamento, na implementação e na avaliação do turismo, para que estes desempenhassem um papel central no fazer turístico. Para que tal acontecesse, seria essencial que houvesse capital social.

Sem o respectivo capital social, o desenvolvimento do turismo de base comunitária ficou seriamente comprometido, pois ações como a participação e o diálogo social, a identificação de recursos e vantagens competitivas locais ou o planejamento e a gestão local da atividade turística tornaram-se praticamente impossíveis de ser alcançados. 
O Brasil, tal como a maioria dos países em escala global, foi despertado para a importância do turismo comunitário como modelo de gestão para o desenvolvimento local.

Deste modo, programas específicos de implementação deste tipo de ação junto às comunidades são desenvolvidos pelo país como no Rio de Janeiro $(\mathrm{RJ})$, onde o turismo de base comunitária é desenvolvido na favela do Alemão (GODINHO; LANÇA, 2018) e por uma cooperativa em Guaraqueçaba (PR) (VALENTE; MIELKE, 2017) onde são mostradas as dificuldades de desenvolver esse modelo de turismo e as potencialidades que esses locais têm e como o engajamento das comunidades é importante para seu desenvolvimento harmônico.

Situação parecida observou-se no Rio Grande do Norte, onde uma Organização Não Governamental (ONG) foi contemplada com um financiamento do Ministério do Turismo, em 2008 (BRASIL, 2008). Esse financiamento teve por objetivo desenvolver ações de turismo comunitário no município de Maxaranguape, e para tal, contou com recursos endógenos de elevado potencial para o desenvolvimento de segmentos turísticos como o turismo rural, de natureza, de sol e mar. Da mesma forma, o município contou também com outro projeto, que igualmente envolveu o turismo de base comunitária, em 2012, chamado Cajusol $^{1}$, desenvolvido por um arranjo institucional entre universidades públicas, agência financiadora do Governo Federal e o Governo Estadual.

Assim, neste trabalho pretendeu-se compreender a influência do capital social no desenvolvimento do turismo comunitário, a partir da experiência ocorrida no município de Maxaranguape, no Estado do Rio Grande do Norte (Brasil).

\section{CAPITAL SOCIAL, PARTICIPAÇÃO COMUNITÁRIA E DESENVOLVIMENTO LOCAL}

A intensificação das relações sociais, econômicas, ambientais, culturais, políticas entre outras, em escala mundial, ligaram localidades distantes espacialmente de tal maneira que acontecimentos locais foram influenciados por eventos que ocorreram em

\footnotetext{
${ }^{\top}$ Fonte: Site do Projeto Cajusol. Acesso em: 20/06/2017. Disponível em: <http://cajusol.proex.ufrn.br>.
} 
outras partes do mundo (GIDDENS, 1991). A isso se chamou de globalização que teve, no modelo econômico do neoliberalismo, uma de suas faces.

$\mathrm{O}$ neoliberalismo caracterizou-se por enfatizar as liberdades individuais em detrimento do poder dos Estados. Defendeu a criação de um comércio livre e acreditou que a lei da oferta e da procura seria suficientemente forte para alcançar o crescimento econômico, regular a economia e propiciar uma justa redistribuição da riqueza, negligenciando qualquer papel de um Estado regulador (CERQUEIRA, 2008; CURY, 2011). Desta forma, concebeu o papel do Estado como mero garantidor da defesa e soberania dos países assim como dos direitos sociais mais básicos, rejeitando a intromissão do mesmo nos sistemas econômicos.

A globalização do modelo neoliberal não contribuiu para combater as desigualdades entre países, tendo inclusive ampliado, em certos casos, os níveis de pobreza e a diferença entre classes sociais. Isso também se aplicou às questões internas dos países (MURTEIRA, 2003).

Devido à incapacidade do Estado em promover os serviços essenciais à sociedade, as atenções voltaram-se ao terceiro setor, para as redes sociais ou capital social, que surgiu como resposta e alternativa de desenvolvimento de uma economia diferenciada. Esta economia diferenciada prezou pela justiça social, pela solidariedade, pela participação, pela democracia, com cidadãos ativos e participativos, imbuídos de engajamento pelo bem comum. Enfim, teve por intenção esboçar a possibilidade de uma sociedade mais humana. Contudo, não se pode ignorar a ambivalência dessa tendência teórica, qual seja: (i) a emancipação da sociedade e seus cidadãos, a eliminação das desigualdades sociais e de distribuição de poder e (ii) a suposta harmonia das comunidades tradicionais (FREY, 2003). A noção de capital social resgatou a ideia de coletividade em prol do bem comum.

Coleman (1990) e Putnam (1993) chamaram de capital social, características das organizações sociais como confiança, normas e sistemas, que contribuíram para aumentar a eficiência da sociedade, facilitando as ações coordenadas.

O termo capital social surgiu por analogia com as noções de capital físico e humano, instrumentos e treino que estimularam a produtividade individual. $\mathrm{O}$ capital social referiu-se a características da organização social, como redes, normas e confiança 
que facilitaram a coordenação e a cooperação para benefício mútuo. O capital social estimulou os benefícios do investimento em capital físico e humano (PUTNAM, 1993).

Para Putnam (1996), capital social significou, pois, um estoque de relações sociais empenhadas numa comunidade, sendo que este baseou seu êxito no fortalecimento da cooperação e da confiança mútuas. O elemento básico do capital social foram as relações de confiança geradas através da cooperação. Confiança, normas e sistemas de participação foram estoques de capital social com vistas ao bem-estar coletivo. Mas o contrário também existiu e prevaleceu, segundo Putnam (1996). Se houvesse desconfiança, se os sistemas de participação fossem precários, estar-se-ia diante de uma comunidade não cívica, do não fazer, do não agir, do não cooperar. "A história determina qual desses dois equilíbrios estáveis irá caracterizar uma dada sociedade" (PUTNAM, 1996, p. 188).

A literatura sobre capital social e redes colaborativas (CAMARINHA-MATOS; AFSARMANESH, 2008) demonstrou que o atendimento às expectativas dos envolvidos foi condição básica para que a confiança ocorresse. Considera-se que a confiança foi essencial para que houvesse capital social. Portanto, o sucesso ou insucesso de uma ação dependeu também do atendimento às expectativas dos atores envolvidos. A continuidade do grupo dependeu de os atores compreenderem que sua ação podia ser fortalecida nesse processo, quando, as expectativas fossem contempladas, se houvesse motivação, confiança, comprometimento, aspectos fundamentais para a coesão de um grupo. Caso contrário o grupo tendeu a se desfazer.

Abramovay (2000) apontou que capital social, portanto, não foi simplesmente um atributo cultural cujas raízes só podiam ser fincadas ao longo de muitas gerações. Ele podia ser criado, desde que houvesse organizações suficientemente fortes para sinalizar, aos indivíduos, alternativas aos comportamentos políticos convencionais. $\mathrm{O}$ capital social faria a diferença na conquista de políticas públicas e gestões políticas mais participativas, portanto, fortaleceria o capital social de um determinado território.

\section{TURISMO E SUSTENTABILIDADE}

No turismo, o desenvolvimento endógeno, que possibilitou oportunidades de geração de emprego e renda para as localidades onde foi desenvolvido (FARIA, 2012) e 
as questões de sustentabilidade ganharam destaque, fez um contraponto ao neoliberalismo que percebeu o turismo somente como uma indústria exportadora. Assim, como nas demais atividades econômicas, ele esteve englobado em um contexto de mercado globalizado. Posto isto, o incentivo ao turismo internacional e à internacionalização dos seus agentes trouxe múltiplos benefícios econômicos aos países menos desenvolvidos, com especial incidência na entrada de divisas, aumento das exportações e de postos de trabalho (CLARKE; NG, 1993).

Contudo, Martoni (2006) e Rodrigues (2002) lembraram que existiu um lado prejudicial do turismo. Estiveram se referindo ao entendimento do turismo apenas como consumidor de recursos, apropriando-se e utilizando o território de forma intensiva, transformando o turismo em mercadoria sacralizada e paga, condizente com o ideal da pós-modernidade. É sempre importante ter presente que, devido ao capitalismo, o turismo surgiu como atividade econômica lucrativa, tecnicista, desconsiderando questões ambientais e histórico-culturais, ou seja, foi mais um negócio. O lucro acima do cultural, do social e do ambiental.

Mas Krippendorf (2003) realçou a necessidade da existência de novos conceitos de implementação turística que privilegiariam as ações para as necessidades das comunidades locais e que se sustentariam na criatividade e no know-how das mesmas, uma vez que elas desejavam ser mais atuantes no fazer turístico, assumindo o protagonismo das suas ações.

Perante os argumentos supracitados, desenvolveu-se o conceito de turismo sustentável que, influenciado pelo modelo do desenvolvimento sustentável, levou em conta fatores ambientais e sociais no desenvolvimento de destinos turísticos. Uma das formas estudadas para aplicabilidade prática de um turismo sustentável foi a implementação de um desenvolvimento turístico endógeno, pela importância que ele atribuiu às infraestruturas naturais ou construídas e ao fator humano.

Sinclair e Stabler (1997) destacaram o papel importantíssimo que o setor público teria na criação de políticas, capacidade de investimento e fiscalização da atividade turística neste tipo de desenvolvimento sendo que, parte do esforço público podia ser recompensado através de impostos diretos e indiretos.

O desenvolvimento turístico endógeno, apesar de comportar investimentos mais reduzidos e não atrair o turismo de massas possuiu uma percentagem de absorção local 
de capital mais elevada do que o desenvolvimento turístico baseado no modelo neoliberal. Isso contrastou com o modelo neoliberal do turismo, onde a fuga de capital para outros países ou regiões acontecia por via de transferências de divisas, pagamento de mão de obra especializada estrangeira ou consumo de recursos não locais. Nesse sentido, Sharpley e Telfer (2008) e Zhang et al. (2007) mencionaram que um desenvolvimento turístico que integrasse a comunidade com um intuito de desenvolvimento humano e sustentável, muitas vezes geraria mais receitas para um destino do que o próprio turismo baseado em agentes internacionais, pelo simples fato de utilizar esmagadoramente recursos locais. A este pensamento estiveram inerentes os efeitos multiplicadores da "indústria turística" nas economias locais.

A premissa máxima do desenvolvimento endógeno do turismo deveria ser garantir a redistribuição equitativa de renda pela população, principalmente pela mais desfavorecida, ao mesmo tempo em que zelasse pela sustentabilidade ambiental do local, mesmo que para isso fosse necessário impor limites à entrada de turistas. $\mathrm{O}$ desenvolvimento turístico deveria sempre respeitar bases de benefícios recíprocos que promovessem a igualdade de direitos e a solidariedade (KRIPPENDORF, 2003).

Mas não se poderia generalizar e dizer que a vertente neoliberal do turismo sempre foi maléfica e que o desenvolvimento endógeno sempre foi a melhor solução, mas sim, foi importante observar e considerar que tipo de turismo foi mais adequado para cada situação (FARIA, 2012; SHARPLEY, 2009). Muitas vezes, o turismo massificado foi a única alternativa e, em outras, o turismo endógeno podia não ser sustentável economicamente.

Para que formas alternativas de turismo pudessem ser desenvolvidas em um local foi necessário que houvesse, nesta sociedade, capital social estocado que correspondesse ao caráter mais cívico, tornando a sociedade mais apta e capaz de superar os dilemas coletivos. Putnam afirmou que "as normas e os sistemas de participação cívica contribuem para a prosperidade econômica e foram, por sua vez, reforçados por esta prosperidade" (PUTNAM, 1996, p. 190). Ou seja, deveria haver cooperação entre os atores que se propuseram a desenvolver o turismo. 


\section{TURISMO E CAPITAL SOCIAL}

O turismo pode ser o propulsor do desenvolvimento local, mas, para isso, seria necessário que houvesse interações verticais, pois uma comunidade que quer atuar no turismo não estaria fora do sistema turístico, mesmo privilegiando as interações horizontais.

O turismo desenvolvido tendo por protagonistas as pessoas do local, em todas as suas etapas de desenvolvimento, precisou de ambiente político, institucional e socioeconômico que fortalecesse as relações de cooperação. Assim como foi necessário que esses atores conhecessem toda a dinâmica da atividade turística. Para isso, a comunidade deveria ser organizada, preparada para tal e, nesse contexto, o capital social foi fundamental para que os objetivos tanto individuais quanto coletivos fossem atingidos.

Segundo Mielke (2009), os atores sociais no turismo tiveram seus próprios interesses e só participariam de projetos coletivos se vislumbrassem benefícios de curto prazo e sem muito envolvimento com os vizinhos, o que foi uma barreira a ser superada para o desenvolvimento de formas alternativas de turismo que tiveram o desenvolvimento endógeno como modelo.

O turismo deveria ser desenvolvido concomitante com as demais atividades econômicas do local que também contribuíram para a formação do produto turístico, havendo agregação de valor para ambos. Isso também faria com que o local mantivesse sua identidade e diminuísse os efeitos negativos da sazonalidade. Essa sinergia contribuiu para que o produto global tivesse um valor social intangível e fortalecesse as relações entre as pessoas de uma dada região (MIELKE, 2009).

A presença da comunidade foi fundamental, através da sua participação em diagnósticos, oficinas, seminários, na construção de propostas, estabelecendo laços de cooperação entre todos os envolvidos.

Nesse contexto, um paradigma turístico que agregou as várias ideologias dos modelos de desenvolvimento alternativos ao modelo neoliberal foi $\mathrm{o}$ turismo comunitário. 


\section{TURISMO COMUNITÁRIO}

O turismo comunitário surgiu como uma alternativa ao atual modelo de desenvolvimento econômico. Ele se baseou em quatro premissas, quais foram: (i) a participação integral da comunidade; (ii) a conservação dos recursos locais; (iii) o desenvolvimento socioeconômico da população e, por fim, (iv) a qualidade e autenticidade da experiência oferecida aos turistas (HIWASAKI, 2006). É uma forma de gestão do turismo que também se contrapôs ao turismo convencional, onde turistas e atores locais quiseram participar ativamente no fazer turístico, com serviços e infraestrutura diferenciados (BURSZTYN et al. 2009). Neste sentido, o turismo comunitário não foi tido como um segmento turístico, e sim, como uma prática (HALLACK; BURGOS; CARNEIRO, 2011). Conforme Maldonado (2009, p. 31) o que distinguiu o turismo comunitário "é sua dimensão humana e cultural, vale dizer antropológica, com objetivo de incentivar o diálogo entre iguais e encontros interculturais de qualidade com nossos visitantes, na perspectiva de conhecer e aprender com seus respectivos modos de vida", corroborando com a ideia de que foi uma forma de gestão e não um segmento.

Para o sucesso da implantação do turismo comunitário, a comunidade deveria ter um papel ativo, desde a planificação até a execução prática do modelo. Deste modo, Irving (2009) afirmou que só existiria turismo comunitário se a população local fosse o sujeito e não o objeto do processo.

O grande atrativo do turismo comunitário foi a possibilidade que o turista teve de interagir com o modus vivendi da comunidade local e, dessa forma, usufruir dos produtos que a mesma teve para oferecer, algo que esteve muito em voga e que foi ao encontro do perfil dos novos turistas traçado por Poon (1994) e que alavancou, incontestavelmente, o comércio e a economia locais, sendo observada também uma distribuição de renda junto da comunidade receptora.

Nesta compreensão, estabeleceu-se uma relação de causa e efeito na interação turista/comunidade receptora. Se, por um lado, o turismo estimulou o aparecimento de atividades comerciais junto às populações locais, por outro lado, o aumento das atividades comerciais fez crescer o interesse do turismo pelo destino, pois este foi estimulado pela diversidade. 
Para Mielke (2009) os projetos de desenvolvimento turístico comunitário ocorreram com um importante apoio de organizações locais do terceiro setor, financiados com recursos governamentais. Via de regra, estes projetos são de curta duração, normalmente com sua execução prevista para o período de um ano, tempo insuficiente para o estabelecimento de relações de cooperação na comunidade. Mas, o tempo mínimo necessário para o estabelecimento de relações de cooperação seria de pelo menos três anos.

O Governo brasileiro veio, aos poucos, fomentando o desenvolvimento da diversificação da oferta turística e, com isso, o turismo endógeno. Para exemplificar, pode-se citar o Edital de Chamada Pública de Projetos MTur/No 001/2008 - Seleção de Propostas de Projetos para Apoio às Iniciativas de Turismo de Base Comunitária (BRASIL, 2008) que contemplou 50 projetos selecionados, distribuídos pelas cinco macrorregiões brasileiras, em 19 Estados. As entidades proponentes foram predominantemente do terceiro setor. Dentre os contemplados, o Rio Grande do Norte teve duas propostas aprovadas (BRASIL, s./d.).

No entanto, as ações de fomento ao turismo, no Rio Grande do Norte, não estiveram ligadas apenas ao Ministério do Turismo. A Fundação de Estudos e Projetos (FINEP), do Ministério da Ciência e Tecnologia, Governo do Estado do Rio Grande do Norte, Universidade Federal do Rio Grande do Norte (UFRN), Universidade Federal Rural do Semiárido (UFERSA), Universidade do Estado do Rio Grande do Norte (UERN), Fundação de Apoio à Pesquisa do Estado do Rio Grande do Norte (FAPERN) e Empresa de Pesquisa Agropecuária do Estado do Rio Grande do Norte (EMPARN) compuseram o arranjo institucional que abarcou ações que envolveram, por exemplo, o Projeto Cajusol $^{2}$.

\section{INICIATIVAS DE TURISMO COMUNITÁRIO EM MAXARANGUAPE/RN}

Apesar de o Estado do Rio Grande do Norte caracterizar-se pelo seu alto potencial de desenvolvimento turístico, com destaque para o turismo de sol e mar, mas também com potencial para o ecoturismo, o turismo rural, de aventura, cultural, dentre outros, a forma de gerir o turismo pelo prisma comunitário ainda foi incipiente.

\footnotetext{
${ }^{2}$ Fonte: Site do Projeto Cajusol. Acesso em: 20/06/2017. Disponível em: <http://cajusol.proex.ufrn.br>.
} 
Foram diversas as ações desenvolvidas neste sentido. Nas comunidades de Diogo Lopes e Barreiras, que fazem parte da Reserva de Desenvolvimento Sustentável Ponta do Tubarão, no município de Macau/RN, foi desenvolvido o projeto Rede Cidadã no Barco Solidário, aprovado em edital do Programa da Petrobrás Desenvolvimento e Cidadania em 2010, com duração até 2012. Porém, o desenvolvimento do turismo não aconteceu, apesar dos atributos que o local tem e das ações já desenvolvidas, para que a atividade aconteça a contento foi observada a necessidade de capacitação e sensibilização das comunidades para que venham a entender o significado do turismo comunitário e como fazê-lo acontecer (GONÇALVES; SILVA, 2017).

Outro exemplo de ação que se assemelha ao que vem a ser o turismo comunitário pode ser observado na comunidade de Pium (municípios de Parnamirim e Nísia Floresta). O projeto chamado de Caminhos de Pium, se configurou mais especificamente como um roteiro desenvolvido pelo Serviço Brasileiro de Apoio às Micros e Pequenas Empresas - Sebrae/RN, com foco no relaxamento, contemplação e contato com moradores locais, sendo as atividades desenvolvidas pelos moradores do local. No entanto, com a saída do Sebrae, o projeto não teve continuidade (LIMA, 2017).

Por fim, tem-se o projeto de turismo comunitário desenvolvido na comunidade de Dom Marcolino (Maxaranguape), mais especificamente no assentamento Novo Horizonte II, o qual foi alvo de análise deste trabalho. Optou-se por este projeto, uma vez que foi este, dentre as situações analisadas, o caso que mais se enquadrou em ações e na abordagem de turismo comunitário, conforme será mostrado ao longo deste artigo.

O município litorâneo de Maxaranguape, como demonstrado na figura 1, está localizado no Polo Costa das Dunas (mais desenvolvido do Estado), distante $54 \mathrm{~km}$ da capital do Estado, município de Natal. Segundo o Instituto Brasileiro de Geografia e Estatística - IBGE (2017), contava com uma população estimada, em 2016, de 12.030 habitantes, com mais da metade na zona rural, estendido por uma área geográfica de $131,30 \mathrm{~km}^{2}$. Segundo o Instituto de Desenvolvimento Sustentável e Meio Ambiente do Rio Grande do Norte (IDEMA, 2013) O município tinha aptidão agrícola para a silvicultura, terras apropriadas para plantio de coco, banana, caju etc., com terras indicadas para preservação da flora e da fauna, nas áreas de dunas. A sua economia teve como principal setor o de serviços, sobretudo relacionado ao turismo. 
FIGURA 1 - MAPA DO ESTADO DO RIO GRANDE DO NORTE E LOCALIZAÇÃO DO MUNICÍPIO DE MAXARANGUAPE E ÁREA DE ESTUDO

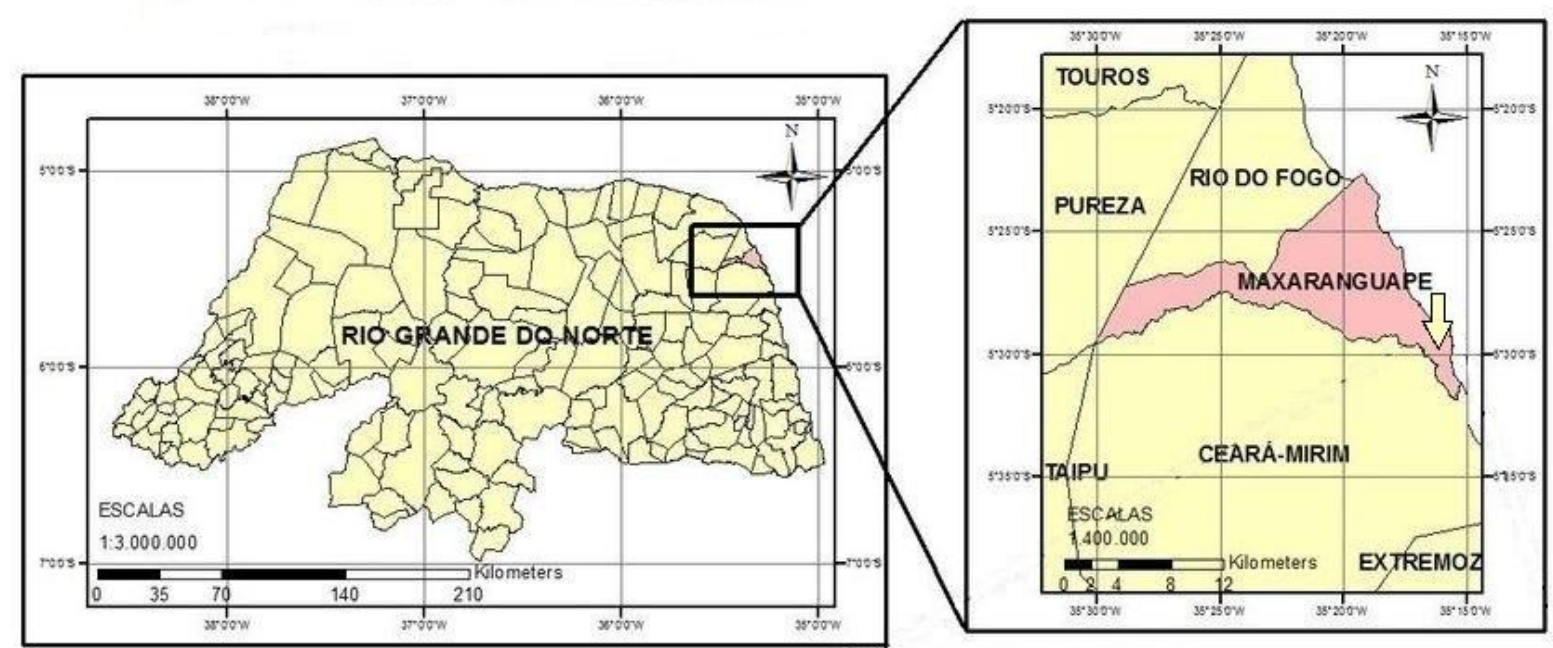

FONTE: adaptado de Silva et al. (2015).

Dentre seus atrativos e recursos turísticos destacam-se as praias de Caraúbas e de Barra de Maxaranguape, com realce para o turismo de segunda residência, pontos de visitação como o Farol de São Roque e Árvore do Amor, além de lagoas, algumas das quais interdunares, com destaque para a lagoa da Cutia (IDEMA, 2013). Há também um rio que corta o município igualmente chamado de Maxaranguape. Porém, é a praia de Maracajaú que recebe o maior fluxo de visitantes do município, por volta de 70 mil anualmente (IDEMA, 2006), pois é dessa praia que saem as embarcações que fazem o passeio ao parracho de Maracajaú (parracho é o nome dado aos recifes de corais no local), que faz parte da Área de Proteção Ambiental do Recifes de Corais (unidade de conservação estadual), e está localizado integralmente na plataforma rasa adjacente aos municípios de Maxaranguape, Rio do Fogo e Touros que ainda contêm os parrachos de Perobas e Cioba (IDEMA, 2006).

Além dos passeios ao parracho, também há os de quadriciclo e a cavalo, para as lagoas do Baião Grande e do Baiãozinho. É importante registrar que os viajantes que vão a Maracajaú, em geral, ficam hospedados em Natal, o que faz com que a maioria dos turistas que se deslocam para esta localidade seja considerada excursionista.

Com relação aos aspectos culturais, constatou-se haver diversas festividades religiosas, como o boi de reis, lapinhas, pastoris, coco de roda, assim como o artesanato de renda de bilros, dentre outros (IDEMA, 2013). 
Assim, como forma de inserir a área rural do município no turismo, em 2008 a ONG Zuzu Angel teve o projeto "Outro Turismo Acontece: turismo solidário e cultura popular nordestina" aprovado no Edital de Chamada Pública de Projetos $\mathrm{MTur} / \mathrm{N}^{\circ}$ 001/2008 - Seleção de Propostas de Projetos para Apoio às Iniciativas de Turismo de Base Comunitária (BRASIL, 2008).

Outra iniciativa para desenvolver o turismo comunitário aconteceu em 2012, por meio do projeto Cajusol, desenvolvido pelas universidades públicas que atuam no Rio Grande do Norte, que segundo informações de seu site, principal fonte de informações sobre o projeto, teve, por objetivo, o desenvolvimento de conhecimentos científicos e de tecnologias sociais nas cadeias produtivas do caju e do girassol, numa perspectiva de criação e estabelecimento de uma economia solidária.

Conforme informações do site, o mesmo funcionou com base nos princípios de incubadora da economia solidária, e foi dividido em dois subprojetos: (i) Cajucultura Solidária no Sertão do RN, desenvolvido nos municípios de Apodi, Caraúbas, Cerro Corá, Lagoa Nova, Mossoró, Severiano Melo e Serra do Mel, e (ii) o Subprojeto Cadeia Produtiva do Girassol no Território do Mato Grande/RN, desenvolvido nos municípios de Bento Fernandes, Caiçara do Norte, Ceará-Mirim, Jandaíra, João Câmara, São Bento do Norte e Maxaranguape, no assentamento Novo Horizonte II. Este último surgiu a partir da luta pela terra em 1998, vinculado ao Movimento dos Trabalhadores Rurais Sem Terra (MST) e reconhecido pelo Instituto Nacional de Colonização e Reforma Agrária (Incra) no ano de 1999.

\section{METODOLOGIA DA INVESTIGAÇÃO}

Em termos metodológicos, a pesquisa para o presente artigo teve uma abordagem metodológica qualitativa, opção realizada por possibilitar compreender, a partir do entendimento e percepção dos atores locais e de atores externos, as relações em torno da temática proposta, ainda incipiente no Estado do Rio Grande do Norte.

Nesse sentido, a escolha qualitativa colocou-se, de acordo com a perspectiva proposta por Bauer (2002), pela necessidade de correlacionar pontos de vista diferentes sobre uma mesma problemática. Ou seja, "o objetivo da pesquisa qualitativa é apresentar uma amostra do espectro dos pontos de vista" (BAUER, 2002, p. 70). 
Com base nas informações do Ministério do Turismo, mais especificamente do Catálogo intitulado Mostra Turismo de Base Comunitária (BRASIL, s./d.), sobre o projeto de turismo comunitário em Maxaranguape, fez-se contato por email e por meio telefônico com a pessoa apontada como responsável pelo projeto. Contudo não se obteve resposta. Outra tentativa foi realizada com outra pessoa da equipe, mas o contato apenas por telefone, uma única vez, e de forma insuficiente para a coleta de dados. Outras tentativas foram efetuadas, mas sem êxito. Acredita-se que o desinteresse das pessoas que naquela época acompanharam este trabalho em atender as solicitações de informações deveu-se pelo desinteresse em esclarecer o que de fato ocorreu.

Com relação ao projeto Cajusol, foi entrevistada a pessoa responsável pela execução das ações de turismo no assentamento Novo Horizonte II. Neste, foram identificadas duas pessoas mais atuantes no desenvolvimento do projeto Cajusol, porém, uma já não morava no assentamento, não sendo possível sua localização. Assim, a entrevista foi realizada com o Presidente do assentamento em exercício em 2012, ocasião da execução do projeto Cajusol. Além dessa entrevista, outras duas foram efetuadas com pessoas que participaram das ações do projeto.

Assim, foram realizadas 4 (quatro) entrevistas, do tipo semiestruturada, em julho de 2017, que consideraram a máxima de Richardson (2008), de que a entrevista semiestruturada é um tipo de estratégia que busca obter, do entrevistado, o seu ponto de vista acerca de um determinado objeto em avaliação. Os eixos das perguntas-guias da entrevista foram: (i) caracterização da ação, (ii) infraestrutura, (iii) economia, (iv) participação social e, (v) caracterização do entrevistado.

As entrevistas seguiram ainda o modelo de entrevista não diretiva, em que o entrevistador lançou um questionamento e o entrevistado explorou a resposta da forma que lhe conviesse. Para maior efetividade de interpretação, foi realizada a leitura através da análise de conteúdo, conforme Bardin (2009).

\section{RESULTADOS E DISCUSSÕES}

Apesar de o Ministério do Turismo divulgar o projeto "Outro turismo acontece: turismo solidário e cultura popular nordestina" como executado (BRASIL, s./d.), tanto 
no contato telefônico com uma das gestoras do projeto, representante da ONG Zuzu Angel quanto na entrevista com o ex-presidente do assentamento Novo Horizonte II (entrevistado 2), afirmou-se que o projeto não aconteceu, o que demonstrou a dificuldade que existia entre o planejamento anunciado pelas políticas turísticas nacionais e a efetiva execução dos projetos aprovados, na realidade local, pelas instituições contratadas. $\mathrm{Na}$ comunidade onde as atividades seriam executadas, ocorreram apenas algumas reuniões preparatórias para formar uma equipe executora, mas nada de efetivo foi realizado. Segundo o entrevistado 2, os recursos não chegaram, mas ainda assim, conseguiram mobilizar ações, junto à Prefeitura, que resultaram na cessão de um restaurante na orla da sede do município e um espaço que servia para reuniões, onde foi montada uma biblioteca. Contudo, o restaurante não chegou a funcionar e o outro espaço, após uma progressiva falta de uso, foi devolvido à Prefeitura, assim como aconteceu com o restaurante.

Restou a busca por informações junto ao projeto Cajusol. Em relação a esse, com base na entrevista realizada com a gestora das ações de turismo (entrevistada 1) e com base nos dados coletados nos sites do projeto ${ }^{3}$ pôde-se observar que o subprojeto desenvolvido na área de estudo tinha como objetivo desenvolver e adequar tecnologias, em contexto participativo e solidário, voltadas à consolidação da cadeia produtiva do cultivo de girassol para a produção de biodiesel, em propriedades rurais familiares. Contudo, havia margem para desenvolver ações secundárias que contribuíssem para que o objetivo principal fosse atingido, no caso, o turismo, uma vez que por meio desse, seria possível escoar a produção agrícola e associada da comunidade.

As ações voltadas para o turismo tiveram início em 2012 e, segundo a gestora, promover ações de turismo foi uma ideia da comunidade, identificada no diagnóstico participativo. As condições para o desenvolvimento do turismo estariam: (i) na proximidade geográfica do assentamento à rodovia BR 101 Norte, que é o caminho para Maracajaú, além de: (ii) da área do assentamento ser contemplada com uma ampla área de Mata Atlântica, com uma zona de transição para a caatinga, sendo as terras do assentamento cortadas pelo rio Maxaranguape, ou seja, o local dispunha de recursos que poderiam ser usados turisticamente. Assim sendo, foi identificada como produto da

\footnotetext{
3 Fonte: Sites do Projeto Cajusol. Acesso em: 20/06/2017. Disponível em: <http://turismoruralnovohorizonte.blogspot.com> e <http://cajusol.proex.ufrn.br>.
} 
ação, uma trilha, bem como o potencial para venda de frutas, verduras, demais alimentos que poderiam ser processados pelos assentados e vendidos aos turistas que fossem fazer a trilha, como também poderiam ser vendidos em um quiosque à margem da BR-101 Norte e na praia de Maracajaú, uma vez que, para essa praia, eles já forneciam alguns produtos. No entanto, a ideia era de que eles mesmos tivessem pontos de vendas para a sua produção e, com isso, eliminariam os atravessadores.

Com base no exposto, naquele momento de desenvolvimento do projeto Cajusol, as quatro premissas para o desenvolvimento do turismo comunitário como alternativa ao atual modelo de desenvolvimento econômico, proposto por Hiwasaki (2006), poderiam ter existido, envolvendo não todos, mas um grupo de pessoas, o que seria o princípio da base da gestão comunitária para o desenvolvimento do projeto.

As ações realizadas pela equipe do Cajusol foram, segundo a gestora (entrevistada 1): a identificação do percurso de uma trilha e a capacitação para o guiamento. Isso se deu, principalmente com jovens do grupo de escoteiros do assentamento. Contudo, essa informação não foi confirmada pelos demais entrevistados. Possivelmente a capacitação aconteceu, mas não no formato ao qual as demais pessoas estavam acostumadas, o que pode ter causado a impressão de que não tenha ocorrido. Outra ação executada, a partir do projeto, foi o replantio de uma área da reserva legal que foi queimada acidentalmente. Além de palestras e oficinas sobre economia solidária com o objetivo de fortalecer o associativismo na comunidade e, na sequência, criar uma unidade de beneficiamento para transformar a produção, assim, agregando valor ao que eles já haviam elaborado. Além da produção vegetal, a ideia era também desenvolver o artesanato local. A comunidade iria se beneficiar com mais produção, transformação, beneficiamento e venda de seus produtos, agregando renda e potencializando o turismo comunitário, o que foi ao encontro do preconizado por Mielke (2009) quando tratou da agregação de valor de mão dupla para as atividades econômicas das localidades.

Constatou-se que a execução do projeto Cajusol deparou-se com problemas desde as pendências burocráticas da associação, passando pela precariedade da infraestrutura existente no local (um barracão e uma casa principal), até a dificuldade do trabalho coletivo, a compreensão do associativismo que, segundo a entrevistada 2, eram muito frágeis. 
A gestora do projeto Cajusol nesta comunidade, entrevistada 2, informou ainda que as reuniões com a comunidade aconteciam na escola, que a assiduidade era cada vez mais baixa, mas que, mesmo com pouca participação, as representações de gênero e geração eram contempladas, com a presença de homens, mulheres, jovens e idosos, e que a decisão das ações acontecia de forma coletiva. Ela afirmou ainda que os pontos fortes para o turismo comunitário, naquela comunidade, eram: a variedade da produção, já que eles tinham um terreno bastante rico, com produção muito diversificada, bem como a localização do assentamento, o que permitia agregar valor ao que eles já produziam. Como pontos negativos, a entrevistada apontou o individualismo e a falta de coletividade.

Para ela, as ações de turismo comunitário não ocorreram no assentamento Novo Horizonte II por falta de interesse da comunidade. Essa constatação corrobora com a premissa desenvolvida por Camarinha-Matos e Afsarmanesh (2008), quando afirmam que o sucesso ou insucesso de uma ação depende também do atendimento às expectativas dos atores envolvidos. A continuidade do grupo dependeu de os atores compreenderem que sua ação podia ser fortalecida nesse processo.

As entrevistas realizadas no assentamento Novo Horizonte II foram três, contudo foi a entrevista com o ex-presidente do assentamento (entrevistado 2) a que mais trouxe elementos para a análise neste trabalho. As demais foram complementares, realizadas com duas senhoras (entrevistadas 3 e 4) que participaram de algumas ações e das reuniões promovidas junto ao Cajusol.

De modo geral, o que foi relatado por elas foi também citado, e com mais detalhes, pelo ex-presidente. Por conseguinte, apareceram com maior frequência informações referentes à narrativa do entrevistado 2 , uma vez que foi ele quem mais lançou memórias sobre o projeto.

Para o entrevistado 2, as ações realizadas pelo projeto Cajusol, referentes ao turismo, foram: (i) identificação do percurso da trilha, (ii) replantio da área de reserva legal, (iii) diagnóstico/planejamento participativo e (iv) plano de trabalho, com as orientações futuras aos assentados, para que dessem sequência às atividades, após a saída dos técnicos do projeto. Ainda, segundo ele (entrevistado 2), a ideia de desenvolver o turismo não partiu da comunidade, e sim, da equipe do Cajusol, o que é contraditório com o que foi relatado pela gestora (entrevistada 1) da área de turismo e 
reforçou o que preconiza Irving (2009), sobre a necessidade de a população local ser o foco central do processo. Provavelmente, se a ideia não surgiu do assentamento, eles não se sentiram sujeitos e sim objetos da ação do Cajusol. Teve-se aqui um indicativo de insucesso do turismo comunitário. No entanto, mesmo a proposta não tendo partido do assentamento, a comunidade aceitou a ajuda do Cajusol para desenvolver ações de turismo comunitário.

A infraestrutura para o desenvolvimento do turismo foi identificada com aquela existente no assentamento e que foi de uso coletivo do mesmo como, um antigo escritório da fazenda (identificado como casa principal) e um galpão, além das casas individuais, dos próprios assentados, informação essa confirmada também pela entrevistada 4.

$\mathrm{O}$ entrevistado 2 reconheceu o empenho dos gestores do projeto em incentivar a participação e que foram deixados subsídios, como o plano de trabalho, para que os assentados dessem continuidade às ações. No entanto, ele reconheceu que, mesmo durante a realização do projeto, a participação nas reuniões já foi baixa, poucos participaram, o que mostrou baixo capital social, com falta de ambiente para o fortalecimento da cooperação e da confiança mútua entre eles (PUTNAM, 1996). Isso possivelmente contribuiu para que, com o fim do projeto, as ações propostas não fossem continuadas.

O motivo apontado pelo entrevistado 2 para o insucesso do projeto foi o mesmo que o da gestora do Cajusol (entrevistada 1), a falta de união das pessoas. Essa constatação foi corroborada pelas outras duas entrevistadas ( 3 e 4) do assentamento.

Além do exposto acima, a entrevistada 3 apontou a falta de atuação do Estado, nas três esferas, o que, segundo ela, contribuiu para a falta de engajamento dos assentados em ações coletivas, alimentando assim, um ciclo vicioso de individualismo, o que foi apontado por Mielke (2009), quando afirmou que no turismo os atores sociais tinham seus próprios interesses e só participariam de projetos coletivos se vislumbrassem benefícios de curto prazo. Para Mielke (2009), há atores dispostos a se sacrificar, mas os benefícios precisam ser vislumbrados, mesmo que em longo prazo, caso contrário ninguém persiste. O próprio ex-presidente do assentamento se disse cansado e, nesse momento, voltou seus esforços para a sua propriedade, sua produção e para a sua família. 


\section{CONSIDERAÇÕES FINAIS}

O turismo comunitário como forma de gestão que propiciasse o desenvolvimento sustentável se configurou como uma possibilidade ainda incipiente no Estado do Rio Grande do Norte. Para compreender suas iniciativas no Estado, neste artigo se buscou compreender a influência do capital social no desenvolvimento do turismo comunitário, a partir da experiência ocorrida no município de Maxaranguape, no Estado do Rio Grande do Norte.

Pode-se afirmar que houve uma contradição entre as informações divulgadas pelo Ministério do Turismo e a realidade encontrada no local, quando se constatou que o projeto de turismo comunitário, em Maxaranguape, não foi executado, diferente do que foi divulgado pelo Ministério do Turismo.

Já o projeto Cajusol teve ações realizadas, porém, não foram continuadas pelo assentamento. Aqui se observou nova contradição, já que as falas da gestora e do assentado foram divergentes com relação à de quem partiu a proposta de desenvolver ações de turismo comunitário, se dos assentados ou do projeto Cajusol.

Posto isto, foi possível observar diversos fatores que desfavoreceram a articulação desse e de outros projetos similares nessa localidade, tais como: a) inexistência de capital social - não havendo confiança, comprometimento, motivação, vontade, credibilidade nas ações; b) baixo protagonismo da comunidade local, com reflexos para a capacidade sócio-organizacional da associação; c) ausência de acompanhamento das ações que ficaram a cargo dos assentados; d) falta de infraestrutura turística e de apoio na comunidade.

De certa forma, as situações que levaram ao insucesso do projeto de turismo de base comunitária em Maxaranguape também foram observadas no caso do turismo comunitário do Rio de Janeiro (RJ) por Godinho e Lança, (2018), em Guaraqueçaba (PR), por Valente, Mielke, (2017) e nas outras duas comunidades do Rio Grande do Norte, como mostrado nos trabalhos de Gonçalves e Silva, (2017), sobre as comunidades de Diogo Lopes e Barreirinhas e a de Pium, no trabalho de Lima (2017).

Em síntese, constatou-se a falta de capital social na comunidade, o que comprometeu o desenvolvimento do turismo comunitário no Município, associada aos demais fatores aqui supracitados. 


\section{REFERÊNCIAS}

ABRAMOVAY, R. O capital social dos territórios: repensando o desenvolvimento rural. Economia Aplicada, 4 (2), abril/junho, 2000.

BARDIN, L. Análise de Conteúdo. Lisboa: Edições 70, 2009.

BAUER, M.; GASKELL, G. Pesquisa qualitativa com texto, imagem e som: um manual prático. Rio de Janeiro: Vozes, 2002.

BRASIL. Ministério do Turismo. Secretaria Nacional de Programas de Desenvolvimento do Turismo. Departamento de Qualificação e Certificação e de Produção Associada ao Turismo. "Edital de Chamada Pública de Projetos MTur/no 001/2008: seleção de propostas de projetos para apoio às iniciativas de turismo de base comunitária”. Brasília, 2008.

Ministério do Turismo. Instituto Casa de Cultura. Mostra: Turismo de Base Comunitária. Brasília, s/d.

BURSZTYN, I.; BARTHOLO, R.; DELAMARO, M. Turismo para quem? Sobre caminhos de desenvolvimento e alternativas para o turismo no Brasil. In: BARTHOLO, R., SANSOLO, D. G.; BURSZTYN, I. (editores). Turismo de base comunitária: Diversidade de olhares e experiências brasileiras. Rio de Janeiro: Letra e Imagem, 2009.

CAMARINHA-MATOS, L.; AFSARMANESH, H. Collaborative Networks: Reference Modeling. New York: Springer Science+Business Media, 2008.

CERQUEIRA, J. Uma Visão do Neoliberalismo: surgimento, atuação e perspectivas. Sitientibus 39, 2008, p.169-189

CLARKE, H.; NG, Y. Tourism, Economic Welfare and Efficient Pricing. Annals of Tourism Research, 20 (1), 1993, p. 613-632.

COLEMAN, J. S. Foundations of Social Theory. Cambridge: Harvard University Press, 1990.

CURY, D. R. O Ideário Neoliberal e as Suas Receitas: base para um estudo da (des)regulamentação jurídica das relações do trabalho. Revista CEPPG, 25(2), 2011, p. 147-165.

FARIA, D. Desenvolvimento e Turismo - uma abordagem conceitual. Belo Horizonte: TD, 2012.

FREY, K. Capital social, estado e democracia. Política e Sociedade, 2, 2003, p. 175187.

GIDDENS, A. As Consequências da Modernidade. São Paulo: Unesp, 1991. 
GODINHO, L. S.; LANÇA, V. S. Turismo de base comunitária: uma possibilidade no Morro do Vidigal (Rio de Janeiro, Brasil)?. Turismo \& Sociedade. Curitiba, v. 11, n. 1, p. 44-68, jan.-abr., 2018.

GONÇALVES, S.; SILVA, G. C. J. Possibilidades do turismo comunitário na Reserva de Desenvolvimento Sustentável Ponta do Tubarão/RN. Caderno Virtual de Turismo. Rio de Janeiro, v. 17, n. 3, p. 82-95, dez. 2017.

HALLACK, N.; BURGOS, A.; CARNEIRO, D. Turismo de base comunitária: estado da arte e experiências brasileiras. Ambientalmente Sustentable, 4 (1), 2011, p. 7-25.

HIWASAKI, L. Comunity-based tourism: A pathway to sustainability for Japan`s protected areas. Society and Natural Resources, 19 (8), 2006, p. 675-692.

IBGE. Instituto Brasileiro de Geografia e Estatística. Disponível em: <http://cidades.ibge.gov.br/xtras/perfil>. Acesso em: 30/07/2017.

IDEMA. Instituto de Desenvolvimento Sustentável e Meio Ambiente. Perfil do seu município: Maxaranguape. 2013. Disponível em: <www.idema.rn.gov.br〉. Acesso em: $13 / 06 / 2017$.

ROM, 2006.

Área de preservação Ambiental dos Recifes de Corais. Disponível em: CD-

IRVING, M. Reinventando a reflexão sobre turismo de base comunitária: inovar é possível? In: BARTHOLO, R.; SANSOLO, D. G.; BURSZTYN, I. (editores). Turismo de Base Comunitária. Rio de Janeiro: Letra e Imagem, 2009.

LIMA, R. M. M. Turismo, políticas públicas e desenvolvimento: uma avaliação do programa de regionalização do turismo nas cinco regiões turísticas do Rio Grande do Norte (2004-2014). Tese (doutorado em Ciências Sociais). Programa de Pós-Graduação em Ciências Sociais, Universidade Federal do Rio Grande do Norte, Natal, 2017.

KRIPPENDORF, J. Sociologia do Turismo: para uma nova compreensão do lazer e das viagens. São Paulo: Aleph, 2003.

MALDONADO, C. O turismo rural comunitário na América Latina: gênesis, características e políticas. In: BARTHOLO, R.; SANSOLO, D. G.; BURSZTYN, I. (editores.). Turismo de base comunitária: Diversidade de olhares e experiências brasileiras. Rio de Janeiro: Letra e Imagem, 2009.

MARTONI, R. Turismo e Capitalismo. Caxias do Sul: UCS, 2006.

MIELKE, E. J. C. Desenvolvimento turístico de base comunitária. Campinas: Alínea, 2009.

MUHANNA, E. Tourism Development Strategies and Poverty Elimination. Problems and Perspectives in Management, 5 (1), 2007, p. 37-49. 
MURTEIRA, M. O que é Globalização, pela invenção dum tempo global e solidário. Lisboa: Quimera, 2003.

POON, A. The New Tourism Revolution in Tourism Management. Elsevier Science. 1994.

PUTNAM, R. D. Making democracy work: Civic traditions in Modern Italy. Princeton: Princeton University Press, 1993.

Comunidade e Democracia: a experiência da Itália moderna. Rio de Janeiro: Editora FGV, 1996.

RICHARDOSON, R. J. Pesquisa social: métodos e técnicas. 3. ed. São Paulo: Atlas, 2008.

RODRIGUES, A. B. Turismo e desenvolvimento local. São Paulo: Editora Hucitec, 2002.

SHARPLEY, R. Tourism development and the environment: beyond sustainability? London: Earthscan, 2009.

SILVA, H.; ALVES, L.; SIQUEIRA, M.; SANTOS, R.; MUSSE, N. Percepção dos Moradores de Barra de Maxaranguape - RN a Respeito do Uso e Ocupação do Solo na Faixa de Praia. Holos 8, 2015, p. 166-179.

SINCLAIR, M. T.; STABLER, M. The Economics of Tourism, Routledge. London, 1997.

VALENTE, T. P.; MIELKE, E. J. C. Evolução e Potencialidades de Inovação do Turismo de Base Comunitária no Município de Guaraqueçaba - PR (Brasil). Turismo \& Sociedade, Curitiba, v. 10, n. 3, p. 1-26, set.-dez. 2017.

ZHANG, J.; MADSEN, B.; Jensen-Butler, C. Regional economic impact of tourism: the case of Denmark. Regional Studies, Cambridge, v. 41, n. 6, p. 839-854, Ago., 2007.

Recebido em: 06-09-2018.

Aprovado em: 06-10-2018.

Versão finalizada para publicação em: 14-03-2019. 